\title{
Malignant Mixed Ovarian Germcell Tumour with Clear Cell Carcinoma in A Post Menopausal Women
}

\author{
Dr. Rejla $\mathrm{R}^{1^{*}}$, Dr. Deepa $\mathrm{S}^{2}$, Dr. S. Sankar ${ }^{3}$
}

${ }^{1}$ Junior Resident, Department of Pathology, Govt. Medical College Kottayam, Gandhi Nagar, Kottayam, Kerala 686008, India

${ }^{2}$ Assistant Professor, Department of Pathology, Govt. Medical College Kottayam, Gandhi Nagar, Kottayam, Kerala 686008, India

${ }^{3}$ Professor and Head, Department of Pathology, Govt. Medical College Kottayam, Gandhi Nagar, Kottayam, Kerala 686008, India

DOI: $10.36348 /$ sijog.2020.v03i04.005 $\quad$ | Received: 20.04 .2020 | Accepted: 27.04 .2020 | Published: 30.04 .2020

*Corresponding author: Dr. Rejla R

\section{Abstract}

Malignant ovarian germ cell tumours are uncommon and it occurs mainly in adolescent age group ${ }^{1}$, and very rarely in post-menopausal period. Clear cell carcinoma ovary occurs in older age groups [1]. They occur either in pure form or maybe associated with other types of germ cell neoplasm. Yolk sac tumours rarely coexists with epithelial carcinoma, and is rare in post- menopausal women. Here we report a case of 60-year-old post-menopausal women with bilateral ovarian malignancy which contained components of clear cell carcinoma and yolk sac tumour. Such a combination of tumours are rare [2].

Keywords: Germ cell tumour, clear cell carcinoma, mixed ovarian tumour, yolk sac tumour, post-menopausal ovarian tumour.

Copyright @ 2020: This is an open-access article distributed under the terms of the Creative Commons Attribution license which permits unrestricted use, distribution, and reproduction in any medium for non-commercial use (NonCommercial, or CC-BY-NC) provided the original author and source are credited.

\section{INTRODUCTION}

Ovarian cancers are the second most common female gynaecological cancers and are the leading cause of death. They commonly arise in $5^{\text {th }}$ to $7^{\text {th }}$ decade of life. Clinical manifestations commonly include abdominal and pelvic pain with bloating, distention, urinary urgency and frequency and unintended weight loss.

Epithelial ovarian cancers cover a majority of malignant ovarian cancers and are classified based on histologic morphology. Malignant germ cell tumour of the ovary accounts for 2-5\% of all ovarian tumours [4]. Mixed germ cell tumours of ovary are malignant neoplasms containing combinations of two or more types of germ cell elements. They are usually diagnosed in young women between the ages of 20 and 30 and accounts for $70 \%$ of all ovarian cancers in this age group. But these are rare in post-menopausal patients [1].

Clear cell carcinoma is of epithelial subtype, makes up about $5-10 \%$ of ovarian cancer ${ }^{5}$. It became recognised as separate category of ovarian cancer by
WHO IN 1973. The neoplastic cells usually contain glycogen with large clear cytoplasm. It may also have associated with endometriosis. This specific subtype carries a generally poor prognosis because of its resistance to standard treatment with platinum and taxane-base agents [6].

\section{CASE HISTORY}

A sixty-year-old parous post-menopausal woman presented with abdominal pain and distension for 2 weeks. On examination a large mass was palpable per abdomen up to the level of umbilicus. On investigation her CA-125 was elevated (1250) and CT scan abdomen showed large well defined mass lesion is seen arising from the pelvis extending up to the umbilicus with mild to moderate ascites was suggestive of a malignant ovarian tumour (Fig-1).

During FDG PET a large solid cystic lesion arising from pelvis and involving bilateral adnexa and extending to umbilical region with heterogeneous enhancement of solid component and non-enhancing cystic areas were noticed. Diffuse omental thickening were also noted. Forewhich chemotherapy followed by 
Rejla R et al; Sch Int J Obstet Gynec, April. 2020; 3(4): 134-137

debulking of the tumour and hysterectomy was done. Intra operatively large friable partially ruptured bilateral ovarian neoplasm were seen. Hemoperitoneum and peritoneal deposits were also seen.

On gross examination (Fig-2) bilateral ovarian tumours with stretched out fallopian tube, right side was weighing about $20 \mathrm{gm}$ and measuring $6 \mathrm{~cm}$ in greatest dimension and left side was weighing 400gm and measuring $15 \mathrm{~cm}$ in greatest dimension. On cut section both had solid and cystic areas were seen largest cyst measuring $5 \mathrm{~cm}$ in greatest dimension. Uterus was weighing $20 \mathrm{gm}$ and measuring $6 \times 5 \times 2 \mathrm{~cm}$. Endometrium and myometrium appeared unremarkable. Omentectomy showed multiple nodularities largest measuring $2 \mathrm{~cm}$ in greatest dimension and cut section was grey white.
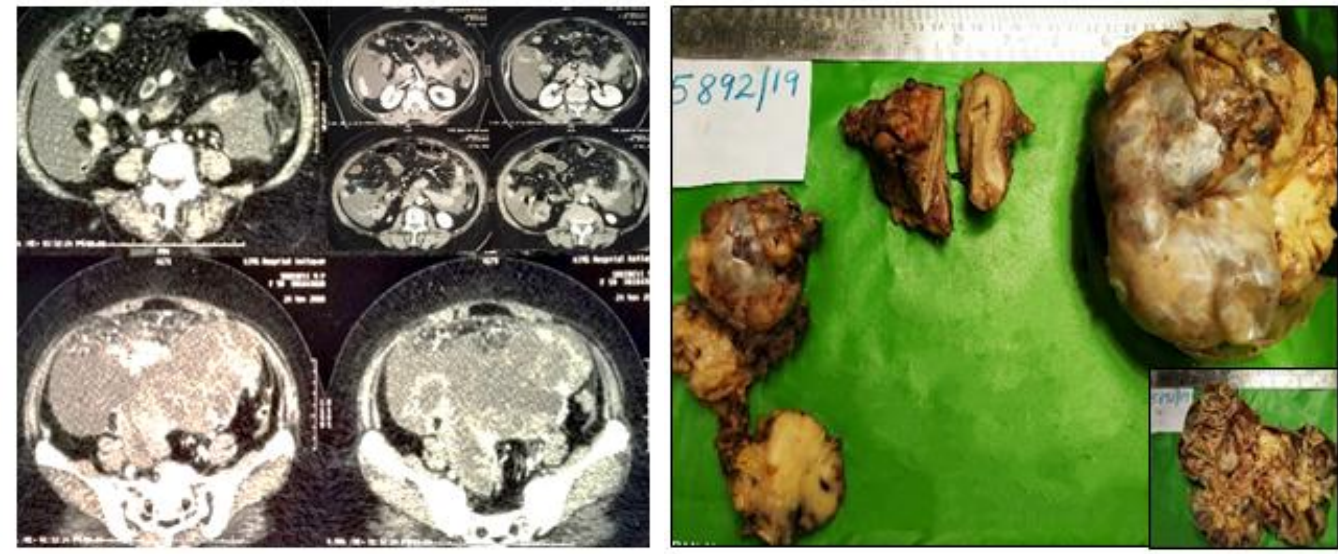

Fig-1: a) Well defined mass lesion arising from pelvis b): The gross appearance of uterus with bilateral ovarian malignancies. Ovarian mass shows solid and cystic areas

Microscopy showed (Fig-3) ovarian tissue with solid and cystic neoplasm composed of different population of cells arranged in sheets, papillary pattern, nests, cysts, poly vitelline pattern and trabeculae. The cells which was arranged in sheets or cystic pattern and poly vitelline pattern are cuboidal and columnar cells with clear cytoplasm. Foci showed sub nuclear apical vacuoles. Numerous hyaline globules and SchillerDuval bodies also seen. These area area constitute $80 \%$ of the neoplasm. Another area composed of cells arranged in sheets and nests are composed of mainly immature mesenchyme and immature squamous cells. A small foci of embryonal carcinoma and syncitiotrophoblasts were seen infiltrating the capsule and serosa of the fallopian tube. Neuroepithelial elements were not seen. Section from uterus showed chronic cervicitis. Omentectomy specimen showed metastasis from above neoplasm with largest one measuring $2 \mathrm{~cm}$.Since the patient had elevated serum CA-125 levels, extensive sampling followed by IHC studies were done. Thus revealed the presence of clear cell carcinomatous areas.
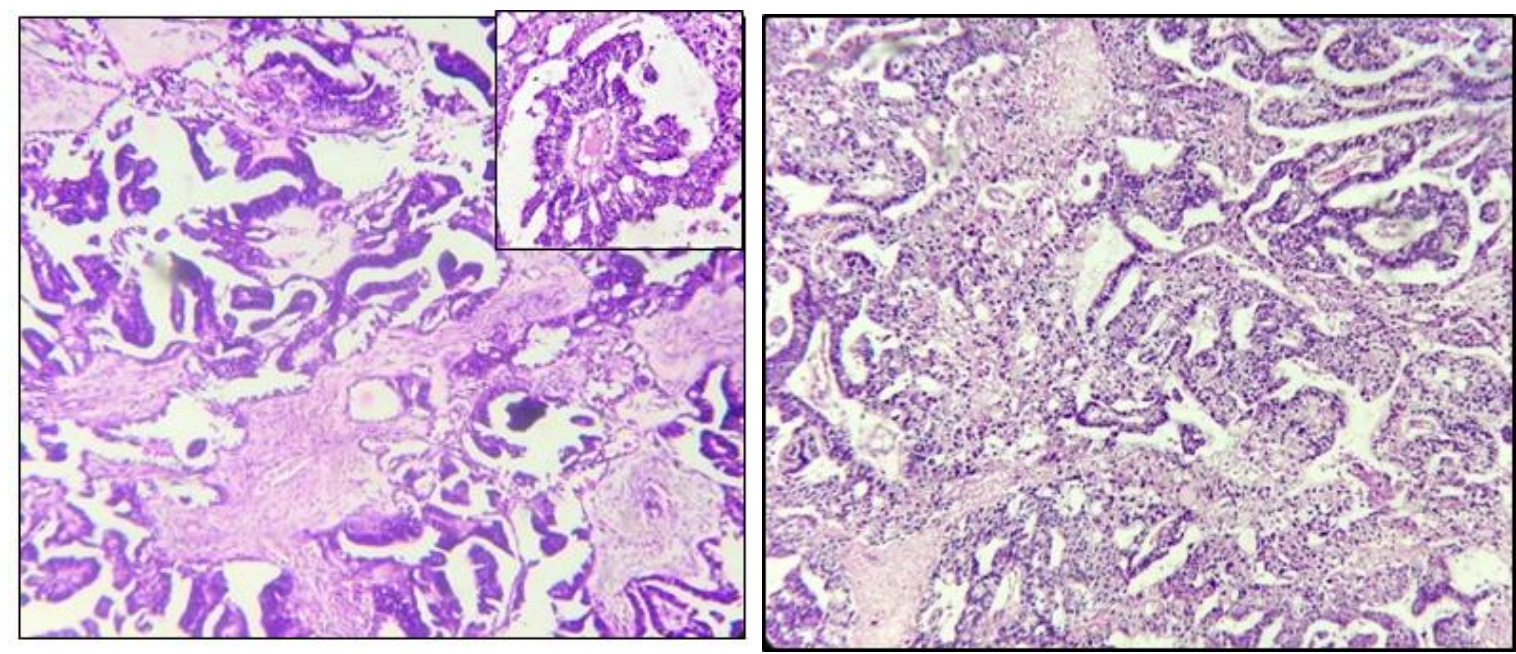

Fig-2: Histopathological appearance of ovarian tumour composed of A) yolk sac tumour B) Clear cell carcinomatous area 

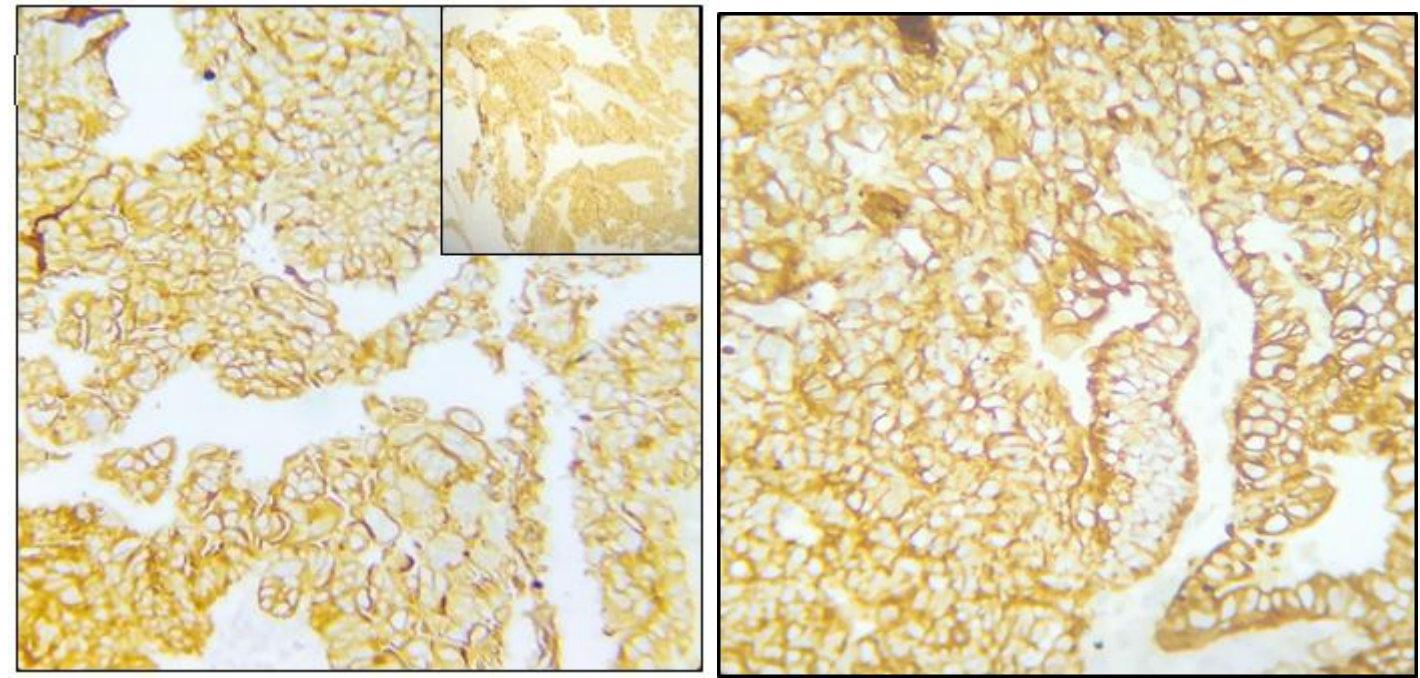

Fig-3: CK, CK7 membranous and EMA positivity

IHC studies (Fig-3) showed tumour cells are positive for CK, CK7 \& EMA in papillary areas. Histopathology was suggestive of malignant germ cell tumour with predominant yolk sac component. So coexisting surface epithelial tumour was confirmed by further histopathologic and IHC studies i.e., clear cell carcinoma. Thus the diagnosis made was mixed ovarian yolk sac tumour with clear cell carcinoma ovary yTNM-T3cNxMx

After surgery she received chemotherapy with BEP regimen. So far she is doing well with no further complaints. The patient is receiving chemotherapy regularly and is advised to have periodic follow up.

\section{DISCUSSION}

Ovarian germ cell tumour are type of ovarian neoplasm principally affecting young women. They are derived from primitive germ cells of the embryonic gonads, and may undergo germinomatous or embryonic differentiation. They differ in clinical presentation, histology and include both benign and malignant subtypes. Germ cell tumours accounts for 15-20\% of all ovarian neoplasm. They constitute the second largest group of ovarian neoplasm, following dysgerminoma [1].

Serum AFB level is elevated in case of most of the yolk sac tumours but this is not routinely measured in older age group with ovarian neoplasm. Usually yolk sac tumour seen in pure forms, if more than one elements are seen then known as mixed germ cell tumour. Little is known regarding ovarian yolk sac tumour in post-menopausal patients. Literature available is limited due to the low incidence. Four theories explain the pathogenesis of germ cell tumour in ovary in post menopause [2]. a) Teratoma theory b) Retro differentiation c) Collision d) Neo metaplasia theory. These neo-metaplasia theory and retro differentiation theories also explains the development of ovarian yolk sac tumour. It states that it is likely to be developed from epithelial neoplasm, known as somatic somatically derived yolk sac tumour. The prognosis of GCT in post- menopausal women is poor. The average prognosis reported is about 8 months [4].

Generally malignant ovarian germ cell tumours are thought to be highly curable with excellent outcome. Increased age over 40 years is a poor prognostic factor for germ cell tumours. Solheim et al., analysed the prognostic significance of age in 2541 patients with Malignant Ovarian Germ Cell Tumour [8], including age greater than 40 is associated with high mortality [9].

Yolk sac tumour in older women are seen either in association with ovarian epithelial tumours or without identifiable epithelial precursor. The clinical features were similar compared to young patients. The disease is aggressive and the outcome remains poor.

Yolk sac tumour which was seen in associated with epithelial tumour is that of the high grade serous carcinoma [10]. In our case yolk sac tumour was seen associated with clear cell carcinoma ovary, which is an uncommon subtype of epithelial ovarian carcinoma. These combination is reported only in 3 literatures [11]. Clear cell carcinoma holds molecular genetic mutation in both ARID1A and PIK3CA, similar to other epithelial ovarian cancers. Mutation in ARID1A commonly contain phosphatase and tensin homolog (PTEN) that are hypothesized to contribute to clear cell tumorigenesis. Inactivation of ARID1A alone does not lead to tumour initiation. Clear cell carcinoma can be associated with thromboembolic complications and hypercalcaemia. Clear cell tumours are usually found in early stage (stage I or II) and has a relatively good prognosis with surgery. However, presentation with advanced disease stage or recurrence has worst prognosis than more common type of serous or endometroid carcinoma. The presence of specific molecular characteristics such as PIK3CA and ARID1A 
Rejla R et al; Sch Int J Obstet Gynec, April. 2020; 3(4): 134-137

mutation and MET gene amplification have been proposed to be associated with chemo resistance [8].

Immunohistochemistry is important in making diagnosis of mixed germ cell tumours. CK7 and EMA are important stains for differentiating YST from epithelial carcinoma. Usually CK7 and EMA are negative in YST and positive in epithelial tumours. AFP and HCG are tumour markers of germ cell origin. AFP is positive in case of most endodermal sinus tumour and embryonal carcinoma while HCG is positive in case of choriocarcinoma and embryonal carcinoma. AFP is negative in epithelia tumours. New markers for YST includes glypican 3 and SLLA-like protein 4 useful in identification of YST component. Glypican- 3 is an oncofetal protein expressed in fetal liver and malignant tumours of hepatocytic lineage, is more sensitive than AFP but nonspecific. SALL4 is a sensitive and specific marker for germ cell tumour.

\section{CONCLUSION}

Mixed Yolk sac tumour -epithelial carcinoma is a rare entity ${ }^{11}$ and should be recognised as aggressive tumour. So extensive sampling of the tumour and correlation with serological markers to be done before reporting a case. Overlap in morphology and immune phenotype may be seen in this mixed tumours, so that pathologist should need a high index of suspicion when reporting a case of yolk sac tumour in order to avoid missing of other elements. Ovarian carcinomas are defined by histologic subtypes with variable outcome, patterns of relapse, and response to therapy. Malignant ovarian germ cell tumour is a very rare condition in post-menopausal women and the survival outcome may be worse according to the literatures.

\section{REFERENCE}

1. Carcangiu, M. L., Kurman, R. J., Carcangiu, M. L., \& Herrington, C. S. (2014). WHO classification of tumours of female reproductive organs. International Agency for Research on Cancer.

2. McNamee, T., Damato, S., \& McCluggage, W. G. (2016). Yolk sac tumours of the female genital tract in older adults derive commonly from somatic epithelial neoplasms: somatically derived yolk sac tumours. Histopathology, 69(5), 739-751.
3. Chan, J. K., Cheung, M. K., Husain, A., Teng, N. N., West, D., Whittemore, A. S., ... \& Osann, K. (2006). Patterns and progress in ovarian cancer over 14 years. Obstetrics \& Gynecology, 108(3), 521-528.

4. Boussios, S., Attygalle, A., Hazell, S., Moschetta, M., Mclachlan, J., Okines, A., \& Banerjee, S. (2015). Malignant ovarian germ cell tumors in postmenopausal patients: the Royal Marsden experience and literature review. Anticancer research, 35(12), 6713-6722.

5. Galili, Y., Lytle, M., Bartolomei, J., Amandeep, K., Allen, N., Carlan, S. J., \& Madruga, M. (2019). Clear-Cell Carcinoma of the Ovary with Bilateral Breast Metastases. Case reports in oncological medicine, 2019:1-4.

6. Itamochi, H., Kigawa, J., \& Terakawa, N. (2008). Mechanisms of chemoresistance and poor prognosis in ovarian clear cell carcinoma. Cancer science, 99(4), 653-658.

7. Moniaga, N. C., \& Randall, L. M. (2011). Malignant mixed ovarian germ cell tumor with embryonal component. Journal of pediatric and adolescent gynecology, 24(1), e1-e3.

8. Solheim, O., Gershenson, D. M., Tropé, C. G., Rokkones, E., Sun, C. C., Weedon-Fekjær, H., \& Fosså, S. D. (2014). Prognostic factors in malignant ovarian germ cell tumours (The Surveillance, Epidemiology and End Results experience 1978-2010). European journal of cancer, 50(11), 1942-1950.

9. Robertson, J. A., Sanday, K., \& Nicklin, J. (2019). Malignant ovarian germ cell tumours in the post menopausal population. Australian and New Zealand Journal of Obstetrics and Gynaecology, 59(2), 285-287.

10. Goyal, L. D., Kaur, S., \& Kawatra, K. (2014). Malignant mixed germ cell tumour of ovary-an unusual combination and review of literature. Journal of Ovarian research, 7(1), 91.

11. Yu, X. J., Zhang, L., Liu, Z. P., Shi, Y. Q., \& Liu, Y. X. (2014). Ovarian malignant mixed germ cell tumor with clear cell carcinoma in a postmenopausal woman. International journal of clinical and experimental pathology, 7(12), 89969001. 